\title{
Real Time Smart Energy Meter and Load Automation
}

\author{
Anandhu Chandran ${ }^{1}$, Akshay Anilkumar ${ }^{2}$, Allen Geo Jacob ${ }^{3}$, AbinTom ${ }^{4}$ Divya S.B ${ }^{5}$ \\ ${ }^{1}$ Student, Mangalam College of Engineering, kottayam,India,anandhuchandran011999@ gmail.com \\ ${ }^{2}$ Student, Mangalam College of Engineering, Kottayam, India,akshayanilkumarsrz1998@ gmail.com \\ ${ }^{3}$ Student, Mangalam College of Engineering, Kottayam, India,allengeojacob@gmail.com \\ ${ }^{4}$ Student, Mangalam College of Engineering, Kottayam, India,abintom73@ gmail.com \\ ${ }^{5}$ Assistant Professor, Mangalam College of Engineering, Kottayam, India,divya.sb@ mangalam.in
}

\begin{abstract}
Electricity plays a major role in day to day life. The most important objective of this paper is to show energy consumption and proper use of devices for energy savings. The idea of this system is to maintain an efficient use of the consumption ofenergy. The objective of this paper is to create awareness about energy consumption and proper use of home appliances for energy savings. The proposed system provides a technical twist to the normal energy meters using IOT and GSM technology. This system measures the power used very accurately sends the usage data to the consumer. Smart meters are advanced sophisticated meters that collect the energy utilization data more accurate than the traditional electric meters and communicate the information back to utility providers for monitoring, controlling and billing purpose.
\end{abstract}

Key words: Arduino, wifi module, IoT, GSM

\section{INTRODUCTION}

Electricity is the driving force behind the development of any country. With the rapid increase in residential, commercial and industrial consumers of electricity throughout the world, it has now become imperative for utilities to devise better and environmentally-safe techniques. The demand for electricity is increasing at an alarming rate. So it is becoming more and more complicated to handle the electricity maintenance and requirements. Therefore, there is an immediate requirement to save as much electricity as possible. Energy saved is energy generated and hence there should be measures to save the electricity. To save the energy consumption there are some potent like energy management system and home automation. Correction minimal power usage and reduction of power wastage are the major objectives for a suitable system. The energy management system helps to savings in the overall expensive. These savings may be come from better utilization of man power, savings in the energy consumption and nonbreakdown in the system. From the electricity board section, the information regarding the bill amount, payment and the preplanned power shut down details are communicated to the consumer. If the customer does not pay the bill in time, the user is informed through a message using IoT. If still the customer does not pay the bill, then as per designated consideration, one alert message will be sent then automatically power connection is disconnected from the remote server. It provides preintimation of power cut details and also the energy consumption on daily basis [6] It Provides an alert if the energy consumption exceeds beyond the certain limit. It also has the facility of terminating the power supply through a message when the residents are out of station to minimize the wastage of energy. It is a suitable way of greater accuracy, information to customer, improved billing. In apartments, the energy meter is far away from the residents. Energy consumption on daily basis, billing details and an alarm for the critical limit indication. These features are implemented using the Arduino, NodeMCU (esp8266) (fig1.3) micro controller and a Global System for Mobile (GSM) module. Esp8266 chip is the wifi module. Which helps in transferring the data through the internet. In case, if internet does not work, a (GSM) Global System for Mobile Communication is used for backup purposes. 
Anandhu Chandran et al ., International Journal of Advances in Computer Science and Technology, 9(6), June 2020, 10 - 14

\section{EXISTING SYSTEM}

The existing model is a time consuming process and itneeds a lot of labour.In the existing energy meter, the meter shows the energyconsumed from the date of installation. The system have lot of technical issues and cannot directly communicated to the customer [1].The billing detail for the energy consumed iscommunicated to the consumer monthly through the help of a labour.

\section{PROPOSED SYSTEM}

The proposed system gives information about power cut and alerts for producing alarm, and the consumption of energy exceeds beyond the specified limit. The main idea of the system is to reduce human dependency to collect the monthly reading for producing the billing report so that the technical problems will be minimized. The advantage of this system is that the energy consumed by each appliance can be monitored by the user with the help of the implemented Node Microcontroller unit (NodeMCU). The information regarding the bill amount and payment, preplanned power shut down details are communicated to the user from the electricity board section. This is done with the help of the implemented wifi module, this component sends an e-mail to the registered email ID that is submitted by the user. The wifi module is installed along with the ardino on the electricity meter. If the bill payment is not done by the consumer within the due date, then the customer is warned with an alert message set via email that is automatically generated by the system. If the customer does not pay the bill even after the alert,[2] then the electricity connection is automatically disconnected from the remote server to the consumers'house.

\section{SYSTEM DESCRIPTION}

The block diagram consists of energy meter (fig 1.1) which is supplied by an AC power supply. The Wi-Fi module and the GSM, Node MCU is supplied by DC power supply. The $5 \mathrm{~V}$ relay act as an electromechanical switch and it is connected to each of the home appliances.

The KSEB dashboard (fig1.2)is a utility dashboard to provide the real-time results by aggregating andextracting value from the devices. This system provides the facility of remotemonitoring,netmeteringandremotedisconnectincaseofele ctricitytheftorlate payment of the bill. This webpage consists of the particular function designed options such as "Unit usageCharge", "Generate bill"," Warning", "Disconnect", "Connect", "Status", "Reset"

The "Generate bill" option is provided on the dashboard used to generate the bill of the respective consumer by real time monitoring and evaluating the collected data i.e the unit usage, amount of the power consumed which is the charge is always been updated. When the utility operator chooses this option a bill is being generated and it is sent to the consumer using GSM technology to a registered number of the consumer

The "Warning" option is used to send the warning message to the consumer about the payment without the charging the fine. This helps the consumer to have an awareness to save the cost of fine. The "Unit usage" is used as a future reference of the data in case of any cross-checking needy times. The "Wi-Fi connection status" option is used to verify the internet availability in the devices which it helps to avoid the theft action from the consumer side leading to the block in real time monitoring of data unit. 


\section{BLOCK DIAGRAM}

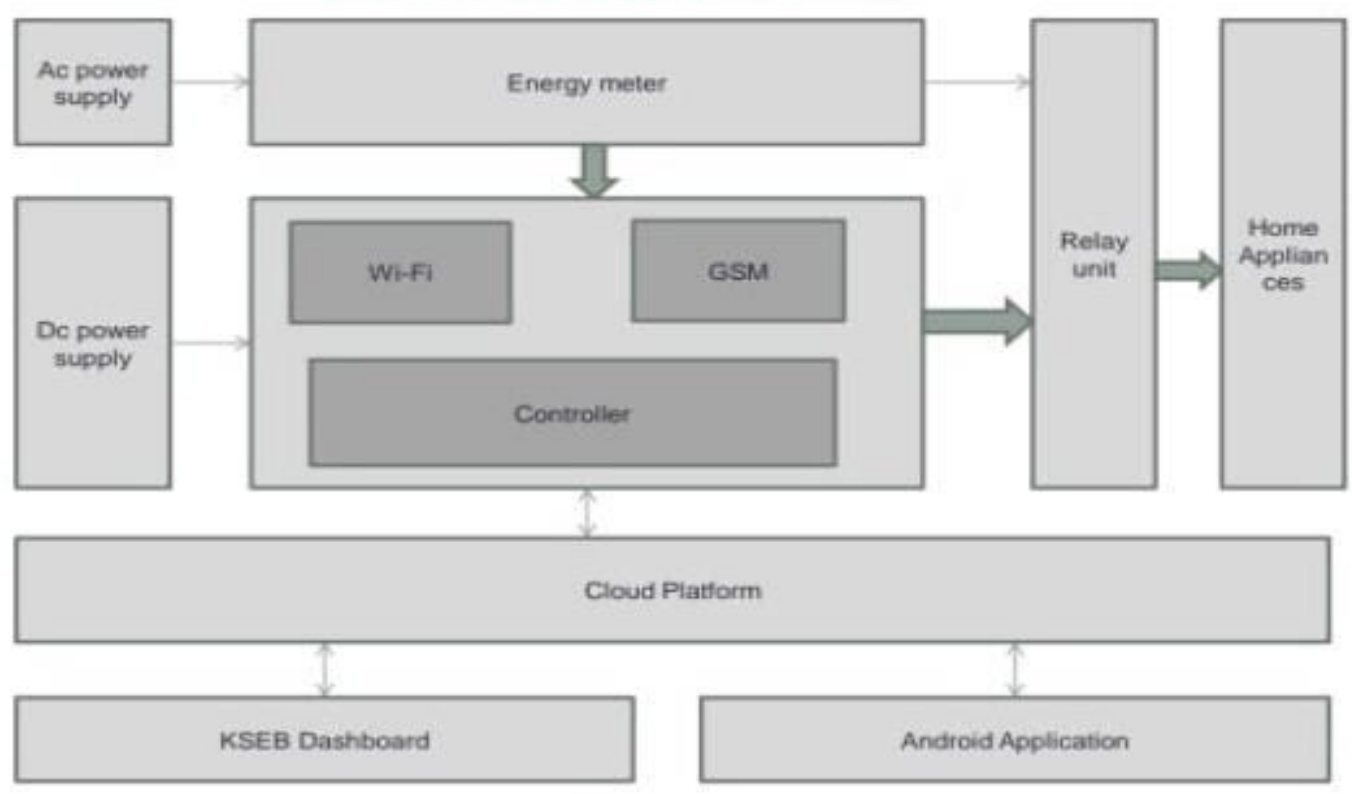

Figure 1: block diagram of the system

The "Connect" and "Disconnect" options can be used in the case where the consumer yet didn't make the payment before the fixed time even after receiving the warning message. The utility dashboard operator can disconnect the supply of the respective consumer As the "Disconnect" option is being selected an appropriate signal is sent to the Node MCU through the cloud to the master relay making this electromechanical switch comes to an normally open condition i.e. the switch OFF position thus discontinuing the supply to the respective consumer. This helps to eliminate the human labor. Similarly the connection can be replaced after making the payment through the same way by selecting the option "Connect" by the utility dashboard operator an appropriate signal is sent to the Node MCU through the cloud to the master relay making this electromechanical switch comes to the closed position i.e the switch ON position thus reconnecting the supply to the consumer.
In this online web accessed system an additional system can also be setupped in favor of consumer efficient energy management thus they can have increased efficiency with low cost system. The load automation system can be developed using both Internet of Things and Global System for Mobile Communication. The load automation by using the IOT the user has an android application where they have a device specified ON/OFF option for automating the home appliances. When the user selects the option for the respectivemode of the device required, an appropriate signal is sent to the Node MCU through the cloud to the respective device relay. If the user requires to ON the device specified, the relay of the respective device comes to the closed condition i.e. the switch is in ON position and the device is ON. Similarly, for the OFF conditionalso. The load automation using GSM technology the users have a registered mobile number to which the message is sent to the Node MCU through GSM module. Thus, the Node MCU sent the appropriate signal to the specified device relay making it to be in normally open or closed condition as per the requirements of the user. 


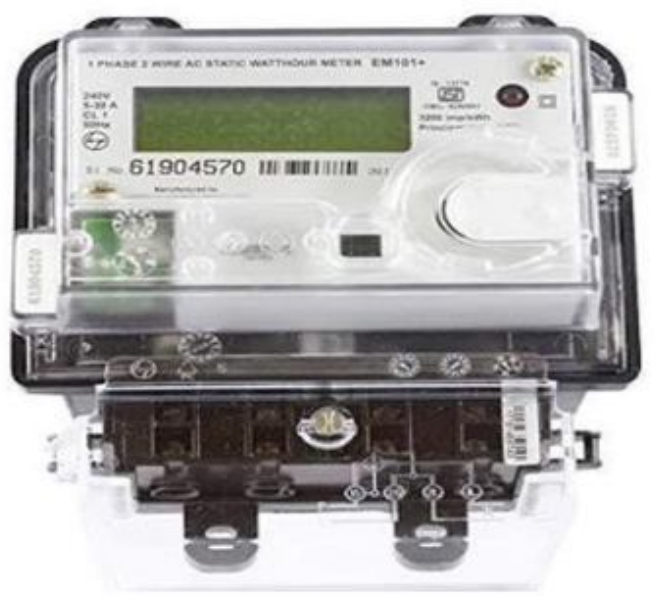

Figure 2: Smart energy meter

\section{A. Energy consumption on daily basis}

In the existing energy meter, the meter shows the energy consumed from the date of installation. In this system, the daily energy consumed is calculated using the arduino micro controller and it is displayed in the LCD. It is also communicated to the consumer's e-mail id with the help of the installed wifi module [2].

\section{B. Alert Systems}

Our electricity billing system has a format that when the energy is consumed beyond the certain limit, double charges are collected i.e. they are charged twice the normal rate. In order to create awareness to the public, an alarm will be provided when the energy consumed by the consumer reaches a nearer value of critical limit. The message is also displayed in the LCD display.

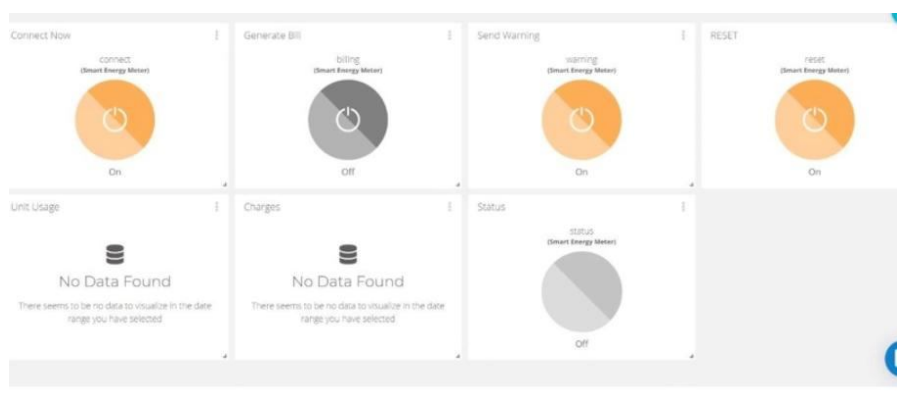

Figure 3: Dashboard view

\section{Monitoring the power consumed by each device}

In our proposed system, if the consumer wants to know the exact usage of the power consumed, it can be checked through the database server. The system keeps track of the power consumed by each device and uploads it to the database server with the help of the wifi module. The consumer can access the database with his registered e-mail to check this and monitor the energy consumed by each device in his house and can find out any unusual or excess usage of power by any device in his house.

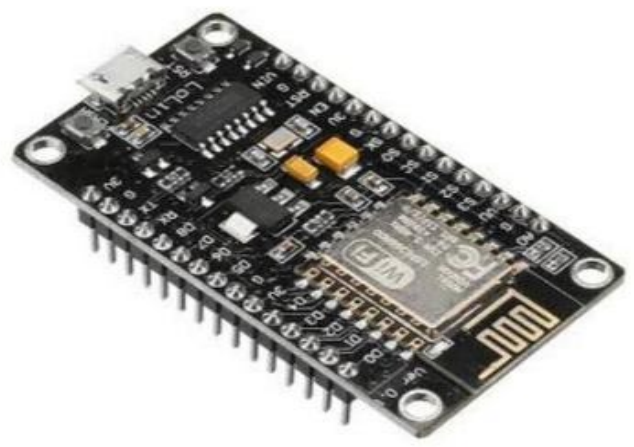

Figure 4:ESP8266 Node MCU

\section{Billing and Payment throughIoT}

The billing detail for the energy consumed iscommunicated to the consumer monthly through the web server using IoT and as a message through the wifi module.The payment is also made through the web server. This helpsin eliminating the manual dependency to collect the reading.

\section{E. Circuit diagram}

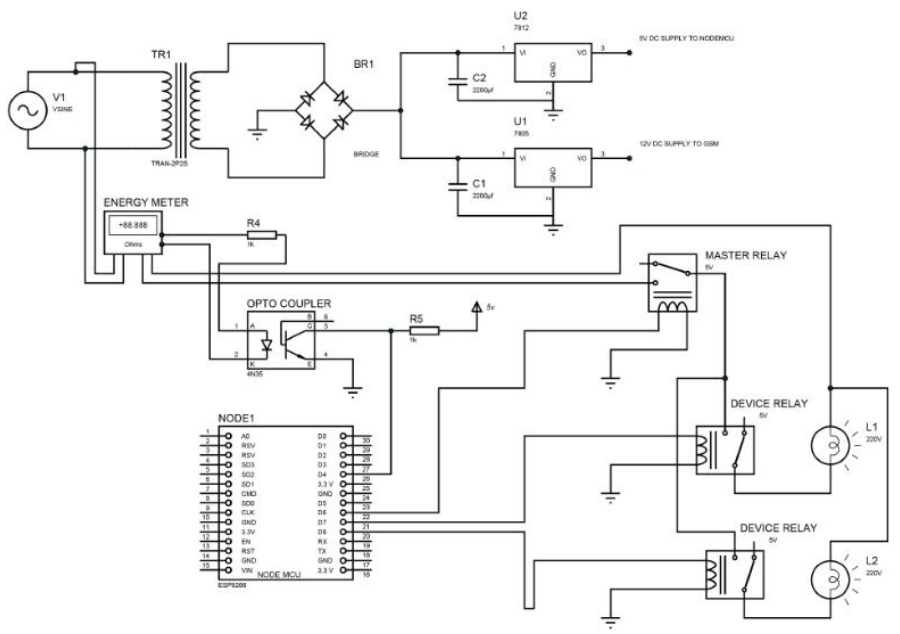

Figure 5: Circuit Diagram 
Anandhu Chandran et al ., International Journal of Advances in Computer Science and Technology, 9(6), June 2020, 10 - 14

\section{ADVANTAGES}

- This system shows the energy consumed on daily basis;hence it helps to reduce the consumption by comparing the daily usages.

- It reduces the human interference to collect the monthly reading and it also saves the time and money.

- The alarm system helps to create awareness to the public regarding their energy consumption and the corresponding charges

-The wifi module helps in saving the data onto the database and also sending mails to the consumer, helping the consumer to monitor the power usage using a smart phone.

\section{CONCLUSION}

The designed energy monitoring system has proven to successfully acquire accurate measurements for energy meter. A very systematic approach has been used for the overall design of this system, in which power consumption factors were to be controlled and monitored. In this paper, we have proposed a smart energy meter which provides better two-way communication with no data loss. The use of web service and SMS service has made it possible to overcome the main limitations of smart meters. IOT and GSM based smart energy meter for advanced metering and billing system is built which is able to read and send data via wireless protocol using GSM technology through GSM module [1], capable of managing the meter as well as the line connection. For GSM module the network coverage of the SIM used is one might be bit complicated due to network strength issues. The implementation of time of monthly billing can control the usage of electricity on consumer side to avoid wastage of power which helps in reduction of energy generation costs. Automation of meter reading gives the information of total load used in a house on request at any time. The introduced system also minimizes the electricity theft in a cost-effective manner. The human labor from kseb office and taking data from energy meter in present day has to pay a good amount of salary for every month. Comparing this smart energy meter saves enough money for every month. In case of line cutting present system is very complex, time consuming and need much labor. But a smart energy meter can easily do these tasks only by sensing the webpage. So a smart energy meter saves time, labor cost andother expensive.

\section{REFERENCES}

1. Himshekhar Das and L.C.Saikia, "GSM enabled smart energy meterand automation of home appliances", Institute of Electrical andElectronics Engineers (IEEE), 2015.

2. V.Preethi and G.Harish, "Design and implementation of smartenergy meter", Institute of Electrical and Electronics Engineers(IEEE), 2016

3. Md.Masudur Rahman, Noor-E-Jannat, Mohd. Ohidul Islam and Md.Serazus, "Arduino and GSM based smart energy meter for advanced metering and billing sytem", Institute of Electrical and ElectronicsEngineers (IEEE), 2015.

4. S.Visalatchi and K Kamal Sandeep, "Smart energy metering andpower theft control using Arduino \& GSM", Institute of Electricaland Electronics Engineers (IEEE), 2017.

5. Gobhinath. S, Gunasundari. N and Gowthami.P, "Internet of Things (IoT) Based Energy Meter", International Research Journal ofEngineering and Technology (IRJET), 2016.

6. P.V. Santhosh Roja, B.Kiran Babu and V. Samson Deva Kumar,"Wireless Energy Meter and Billing via SMS", International Journalof Science and Research (IJSR), 2013.

7. Vanishree k Rao and Sri G N Madhu, "GSM based Energy MeterReading and Billing", International Journal of Science and Research(IJSR), 2016.

8. Pritee Mahajan, SnehaTatia and Prachi Jadhav, "Smart Meter: AnIOT Based Meter for Live Electricity Monitoring and Bill Payment", International Journal of Electrical, Electronics and Computer Systems (IJEECS), 2017. 